In my presentation I will showcase the State of the Art technologies of biomarker research and how the information that comes from this can be implemented for improving clinical care. I will discuss the revolution of molecular profiling and how the large amount of data coming from these approaches is used to molecularly classify patients into molecular fingerprints. How this technology leads to a disruptive change in medicine for the coming 5-10 years. I will close of with the role of biomarkers in the treatment of diseases, trial design and drug development for the coming 5 years.

Disclosure of Interests: None declared

DOI: 10.1136/annrheumdis-2019-eular.8568

\section{SP0160 DISEASE REMISSION: DO WE AIM FOR THE SAME THING?}

Ricardo Ferreira. Centro Hospitalar e Universitário de Coimbra, EPE, Rheumatology, Coimbra, Portugal

It is consensually accepted that the most important therapeutic goals for treating rheumatoid arthritis (as well as other inflammatory arthritis) are eliminating signs and symptoms (such as joint pain, swelling, and stiffness); preventing joint damage or its progression; and maximizing physical function and quality of life (Aletaha \& Smolen, 2019). According to current medical knowledge, these aims are believed to be best accomplished by achieving disease remission, a state in which no or only minimal residual inflammation is discernible (Aletaha \& Smolen, 2019). However, different studies have been providing evidence that achieving inflammatory remission is not enough as a considerable proportion of patients with no or minimal inflammation remain with high levels of pain, fatigue, functional impairment, mental health problems, among other symptoms (Boone et al., 2019; Ferreira et al., 2019; Ferreira et al., 2017). The perfect path to achieve good results is still to be defined, namely, regarding the T2T strategy (van Vollenhoven, 2019). Recent studies still show that despite a high level of patient agreement with RA T2T, patient engagement in this process needs to be improved in order to individualize therapy adjustments, make shared decisions and decide on targets that accurately reflect disease control according to patients (Benham et al, 2019). In this session I would address the following questions:

- Is aiming for one target enough nowadays?

- Do health professionals and patients aim for the same thing when defining treatment strategies?

- Do the current treatment targets pose a risk of overtreatment with immunosuppressive therapy?

This presentation is informed by current research in this area including research from our own group (Ferreira et al., 2018; Santos et al., 2018).

\section{REFERENCES:}

[1] Aletaha, D., \& Smolen, J. S. (2019). Achieving Clinical Remission for Patients With Rheumatoid Arthritis. JAMA, 321(5), 457-458. doi:10.1001/ jama.2018.21249

[2] Benham, H., Rutherford, M., Kirby, S., Stebbings, S., White, D., Sim, D., \& Harrison, A. (2019). Treat-to-target in rheumatoid arthritis: Evaluating the patient perspective using the Patient Opinion Real-Time Anonymous Liaison system: The RA T2T PORTAL study. International Journal of Rheumatic Diseases. doi:10.1111/1756-185x.13514

[3] Boone, N. W., Sepriano, A., van der Kuy, P. H., Janknegt, R., Peeters, R., \& Landewe, R. B. M. (2019). Cotreatment with methotrexate in routine care patients with rheumatoid arthritis receiving biological treatment yields better outcomes over time. RMD Open, 5(1), e000836. doi:10.1136/ rmdopen-2018-000836

[4] Ferreira, R. J. O., Carvalho, P. D., Ndosi, M., Duarte, C., Chopra, A., Murphy, E.,. . . da Silva, J. A. P. (2019). Impact of patient global assessment on achieving remission in patients with rheumatoid arthritis: a multinational study using the METEOR database. Arthritis Care Res (Hoboken). doi:10.1002/acr.23866

[5] Ferreira, R. J. O., Dougados, M., Kirwan, J., Duarte, C., de Wit, M., Soubrier, M.,. . . Gossec, L. (2017). Drivers of patient global assessment in patients with rheumatoid arthritis who are close to remission: an analysis of 1588 patients Rheumatology. doi:10.1093/rheumatology/kex211

[6] Ferreira, R. J. O., Ndosi, M., de Wit, M., Santos, E. J. F., Duarte, C., Jacobs, J. W. G.,. . . da Silva, J. A. P. (2018). Dual target strategy: a proposal to mitigate the risk of overtreatment and enhance patient satisfaction in rheumatoid arthritis. Annals of the Rheumatic Diseases. doi:10.1136/ annrheumdis-2018-214199

[7] Santos, E. J. F., Duarte, C., Ferreira, R. J. O., Pinto, A. M., Geenen, R., \& da Silva, J. A. P. (2018). Determinants of happiness and quality of life in patients with rheumatoid arthritis: a structural equation modelling approach. Annals of the Rheumatic Diseases, 77(8), 1118-1124. doi:10.1136/annrheumdis-2017-212934

[8] van Vollenhoven, R. (2019). Treat-to-target in rheumatoid arthritis - are we there yet? Nature Reviews. Rheumatology, 15(3), 180-186. doi:10.1038/ s41584-019-0170-5

Disclosure of Interests: None declared

DOI: 10.1136/annrheumdis-2019-eular.8477

\section{SP0161 LOOKING FOR A NEEDLE IN A HAYSTACK: HELPING YOUNG PEOPLE TO MAKE SENSE OF EVIDENCE BASED HEALTH CARE}

Simon Stones. University of Leeds, School of Healthcare, Leeds, United Kingdom

While it has been suggested that there are no differences in the occurrence of risk-taking behaviours in young people with chronic conditions compared with healthy peers, young people with chronic conditions often face the dilemma of balancing twice the amount of risk to that of other young people, owing to their condition and treatment. For example, young people with juvenile idiopathic arthritis taking methotrexate face the risks of alcohol consumption plus the increased risk of toxicity from consuming alcohol while taking methotrexate. However, such issues are often ignored or overlooked (1).Research has suggested that a lack of experience with, and not worrying about serious health consequences may desensitise young people with chronic conditions to potential health risks (2). It is also recognised that young people's perceived focus of health and wellbeing can often be on short-term goals; which is often paradoxical to the focus of families and healthcare professionals thinking about longer-term outcomes and prognosis.

It has been demonstrated that young people with chronic conditions value interventions that enable them to live a "normal" life - extending beyond the clinical management of their condition (3). The emotional, social, and vocational conse quences of condition management can be profound (4). When this is coupled with the challenges of accessing accurate, trusted and individualised information and support, it can often leave young people and their families feeling as though they are looking for a 'needle in a haystack'. Finding the best evidence requires knowledge of the best quality and most appropriate sources, as well as the ability to use and navigate such resources appropriately (5). In an era where health information is easier and faster to find than ever before, it is often a challenge for young people to be able to filter the 'good' from the 'not so good'. There are significant amounts of unreliable and irrelevant content on the internet, which ultimately places the responsibility for interpretation of information and advice onto young people and their families.

Therefore, age- and developmentally- appropriate opportunities to discuss health wellbeing and the effects of treatment need to be provided early and regularly, across the lifecourse, in multiple formats to suit individual needs and circumstances. Attempts have already been made to make health information more accessible, for example, with the introduction of the Accessible Information Standard within the National Health Service (6). However, this is not necessarily enough to engage and support young people with chronic conditions in making sense of evidence-based healthcare. Information needs to be taken, in the right formats, to where young people are interacting, such as on certain social media platforms. This needs to be multifaceted, using peer- and community-driven approaches to enhance engagement. Furthermore, periodic consideration of the long-term risks and benefits of health and wellbeing interventions needs to happen across the lifecourse, both as a prompt for young people to air their concerns, but to also check their understanding. Only through understanding young people's values, preferences, and concerns can a sustainable balance between condition control, treatment burden and quality of life be achieved.

\section{REFERENCES :}

[1] McDonagh JE. Getting It Right For Young People: Developing Adolescent Rheumatology Services. Future Rheumatol 2008; 3(2):133-41.

[2] Greening L, et al. Predictors of children's and adolescents' risk perception. J Ped Psych 2005; 30(5):425-35.

[3] van Houtum L, et al. Do everyday problems of people with chronic illness interfere with their disease management? BMC Public Health 2015;15:1000.

[4] Hart RI, et al. Being as normal as possible: how young people ages 16-25 years evaluate the risks and benefits of treatment for inflammatory arthritis. Arthritis Care Res 2016; 68(9):1288-94.

[5] NHS England. Accessible information: Specification v1.1. 2017. 